\title{
Microwave-assisted Extraction and RP-HPLC Quantification of Bergapten from Pithecellobium dulce
}

\author{
S. D. KATEKHAYE* AND K. S. LADDHA \\ Medicinal Natural Product Research Laboratory, Department of Pharmaceutical Sciences and Technology, \\ Institute of Chemical Technology, Mumbai-400 019, India
}

Katekhaye and Laddha: MAE and RP-HPLC Quantification of Bergapten from Pithecellobium dulce

\begin{abstract}
A comparative extraction efficiency study was performed for microwave assisted and other conventional extraction techniques. An accurate, precise and validated reverse phase high-performance liquid chromatography method was developed for estimation of bergapten from Pithecellobium dulce. Several parameters which can potentially affect the extraction yield, namely extraction technique, microwave power, extraction time and solid-liquid ratio were studied. The extraction conditions of microwave assisted extraction were optimized at extraction time of $10 \mathrm{~min}$, microwave power of $700 \mathrm{~W}$ and solid-liquid ratio of $1: 20 \mathrm{~g} / \mathrm{ml}$. The amount of bergapten in samples was analysed by reverse phase high-performance liquid chromatography using isocratic solvent system with chromatographic conditions of acetonitrile:water $(65: 35, \mathrm{v} / \mathrm{v}), \mathrm{RP}$ column $(4.6 \times 250 \mathrm{~mm}, 5 \mu \mathrm{m})$, flow rate of $1.0 \mathrm{ml} / \mathrm{min}$ and $\mathrm{UV}$ wavelength $\mathrm{of} 266 \mathrm{~nm}$. Under optimum conditions, linearity was obtained in the range of $0.5-10 \mu \mathrm{g} / \mathrm{ml}$, with the correlation coefficient $\left(R^{2}\right)$ above 0.996. Intraday $(n=3)$ and interday $(n=3)$ precisions for retention time and peak area were found to be less than 0.5 and $1.5 \%$, respectively. The limit of detection and limit of quantification were 1.0 and $3.77 \mu \mathrm{g} /$ $\mathrm{ml}$, respectively. The recovery expressed in relative standard deviation for the spiked compound at different concentrations $(10,20$ and $30 \mu \mathrm{g} / \mathrm{ml})$ was in the range of $0.95-1.09 \%$. The developed microwave assisted extraction can be used as an alternative procedure to the conventional extraction techniques. The developed analytical method for estimation of bergapten has been demonstrated to be accurate, precise and reliable as per International Conference on Harmonisation guidelines.
\end{abstract}

Key words: Pithecellobium dulce, coumarin, RP-HPLC, analytical method development, conventional extraction techniques

Coumarins represent a biologically important class of phytochemicals for dermatological complications. Bergapten is a fumaro-coumarin, which has acquired a place in the treatment of psoriasis and other dermatoses $^{[1]}$. It also showed platelet aggregation inhibitory activity ${ }^{[2]}$. In recent times, the advancement in herbal research has arisen with many new techniques for extraction and analysis of biomarkers in plant extracts and their formulations ${ }^{[3-5]}$. Conventional extraction techniques like heat-reflux extraction (HRE), soxhlet extraction (SE) and cold maceration are time-consuming, laborious and solvent consuming methods. Recent techniques such as supercritical fluid extraction (SFE), pressurized fluid extraction (PFE), ultrasonic-assisted extraction (UAE) and microwaveassisted extraction (MAE) have become of interest as alternatives to conventional methods. Amongst these, MAE is the simplest and the most economical technique for the extraction of organic compounds from plant materials ${ }^{[6]}$. MAE has many advantages such as short extraction time and lower consumption of solvent to extract biologically active compounds from different matrices ${ }^{[7]}$. Recent reports showed MAE extensively employed for extraction of glycyrrhizic acid from liquorice root ${ }^{[8]}$, isoflavonoids and saponins from Radix astragali ${ }^{[9]}$ and paclitaxel from Taxus baccata $^{[10]}$. Reverse phase high-performance liquid chromatography (RP-HPLC) frequently used for analysis of individual molecule or multiple components by simultaneous analysis employing different detectors $^{[11-13]}$.

This is an open access article distributed under terms of the Creative Commons Attribution-NonCommercial-ShareAlike 3.0 License, which allows others to remix, tweak, and build upon the work non-commercially, as long as the author is credited and the new creations are licensed under the identical terms.

Accepted 20 October 2016

Revised 14 October 2016

Received 08 December 2015

Indian J Pharm Sci 2016;78(5):673-679 
Pithecellobium dulce (Roxb.) Benth is commonly identified as Vanya chincha and found throughout India and in some parts of China and South East Asia ${ }^{[14]}$. The generic name was discovered from the Greek word as Pithekos meaning an ape and lobos referring to a pod. The species name as 'dulce' in Latin means sweet in allusion to the edible pulp of the pod. Because of a resemblance of the fruit to the Indian sweet Jalebi, the plant is also given the name Jungli jalebi $i^{[15]}$. The plant has many food applications in various parts of India. Arils are used in the preparation of beverages ${ }^{[16]}$. Seeds are particularly rich in proteins and peptides and have potential to combat protein malnutrition. The decoction of seed is excellent medicine for the treatment of anemia $^{[17]}$. The pulp is used for the preparation of sweet drinks and seeds are taken as curries (Indian spicy liquid delicacy). It's multiple roles include edible use of the pods, seeds and honey ${ }^{[18]}$.

The plant is used as an abortificient ${ }^{[19]}$, antifunga ${ }^{[20]}$, antivenom $^{[21]}$, antimicrobial ${ }^{[22]}$, hepatoprotective ${ }^{[23]}$, as a cure for intestinal disorders, ear and tooth ache ${ }^{[24]}$, antidiabetic $^{[25]}$ and to treat inflammation ${ }^{[26]}$. The leaves are applied as plasters for pain and venereal sores ${ }^{[24]}$. $P$. dulce is reported to contain an important class of phyto constituent coumarins such as bergapten ${ }^{[27]}$, saponin glycosides like glycosides of oleanolic and echinocystic acids ${ }^{[28]}$, acylated triterpenoid $\operatorname{saponin}^{[29]}$, flavonoids apigenin ${ }^{[30,31]}$, triteepenoids, which includes lupeol, long chain aliphatic hydrocarbons such as lauric $\operatorname{acid}^{[32]}$ and tannins ${ }^{[33]}$.

The literature survey suggests that there are no reports on the effect of different extraction techniques on coumarin content in $P$. dulce. We also observed that no HPLC method is available for quantitative estimation of coumarins in $P$. dulce. Therefore, considering the biological importance of $P$. dulce and bergaptent, the present study was carried out focusing on comparative studies between MAE and conventional method's extraction efficiency. We have also developed and validated RP-HPLC method for quantitative estimation of bergapten.

\section{MATERIAL AND METHODS}

P. dulce bark was collected from Mumbai, India, in November 2010. The plant material was authenticated and voucher specimen (ICT/2010/NP/06) was deposited in the Institute of Chemical Technology, Mumbai. The standard bergapten was purchased from THS Pvt. Ltd., Mumbai, India. Acetonitrile (S. D. fine-chem. Mumbai, India), methanol (Merck, India) were of HPLC grade.
Purified Milli-Q water (Millipore, Bedford, USA) was used for experiments. All other solvents and chemicals used were of analytical grade.

A microwave (2000 MHz magnetron, Realtech, Mumbai), Ultrasonicator (DL-120A, Shanghai Zhixin Instrument Co.) were employed for extraction. HPLC analysis was performed on a Jasco (Hachioji, Tokyo, Japan) system, an intelligent pump (PU-1580, PU2080), a high-pressure mixer (MX-2080-31), and a manual sample injection valve (Rheodyne 7725i). Injection loop volume- $20 \mu \mathrm{l}$, variable wavelength programmable UV/Vis detector (UV-1575), and Borwin software was used.

\section{Microwave-assisted extraction:}

Dried $P$. dulce powder (2 g) was extracted using MAE with $40 \mathrm{ml}$ chloroform. Samples $(1 \mathrm{ml}$ each) were collected after 2, 4 and 10 min time intervals. An equal volume of fresh chloroform was transferred after each sampling. The extracts were concentrated to dryness and reconstituted in HPLC grade methanol $(1 \mathrm{ml})$. The extracts were filtered through a $0.45 \mu \mathrm{m}$ membrane filter prior to HPLC analysis. In this study, the extractive value was calculated using the following formulae, and the results were expressed as mean yield \pm standard deviation $(\mathrm{SD})$. Amount $(\mathrm{mg} / \mathrm{g})=$ mean mass of the active compounds in the sample $(\mathrm{mg}) /$ mean mass of the herb sample (g).

\section{Heat reflux extraction:}

Dried $P$. dulce powder $(2 \mathrm{~g})$ was extracted in a water bath using $40 \mathrm{ml}$ chloroform in a two-neck flask (100 $\mathrm{ml})$ with condenser provided on the top. Samples (1 $\mathrm{ml}$ each) were collected at 2, 4 and $6 \mathrm{~h}$ period. Equal volumes of fresh chloroform were added to the round bottomed flask (RBF) after each sampling. Further steps were followed as given in section MAE.

\section{Soxhlet extraction:}

Dried $P$. dulce powder $(2 \mathrm{~g})$ was extracted in a Soxhlet apparatus with $80 \mathrm{ml}$ chloroform in a two neck round bottom flask. Samples (1 ml each) were collected at 3, 6, 9, 12 and $16 \mathrm{~h}$. Equal volumes of fresh chloroform were added to the RBF after each sampling. Further steps were followed as given in section MAE.

\section{Maceration:}

Dried P. dulce powder ( $2 \mathrm{~g}$ ) was placed inside a stopper fitted flask containing $40 \mathrm{ml}$ chloroform. Samples (1 $\mathrm{ml}$ each) 6, 12 and $24 \mathrm{~h}$ were collected. Equal volume 
of fresh chloroform was added to each flask after each sampling. Further steps were followed as given in section MAE.

\section{Ultrasonic-Assisted extraction:}

Dried $P$. dulce powder (2 g) was placed inside stopper fitted flask with $40 \mathrm{ml}$ chloroform and subjected to ultrasonication. Samples (1 $\mathrm{ml}$ each) at intervals 20 , 40 and 60 min were collected. Equal volume of fresh chloroform was added to each flask after each sampling. Further steps were followed as given in section MAE.

\section{HPLC analysis:}

The HPLC was performed by using Xterra MS C-18 column $(250 \times 4.6 \mathrm{~mm}, 5 \mu \mathrm{m})$ at ambient temperature. The mobile phase consisting of acetonitrile:water $(65: 35 \%, \mathrm{v} / \mathrm{v})$ with a flow rate of $1.0 \mathrm{ml} / \mathrm{min}$, injection volume was $20 \mu \mathrm{l}$ and UV detection wavelength of 266 $\mathrm{nm}$ for employed for analysis. The analytical method was developed for the generation of chemo profile and quantitative estimation of bergapten in $P$. dulce using a combination of solvent systems. The suitability of the solvent system was decided based on run time, cost and sensitivity of the method.

\section{Preparation of standard and sample solutions:}

A stock solution of bergapten $(1 \mathrm{mg} / \mathrm{ml})$ was prepared using HPLC grade methanol in a $10 \mathrm{ml}$ volumetric flask. The stock solution was then used for the preparation of calibration curve and was stored at $-20^{\circ}$ until analysis. Reconstituted samples obtained from each extraction technique were used for quantification of bergapten and were stored at $-20^{\circ}$ until analysis.

\section{Preparation of calibration curve:}

Quantification of bergapten was performed using the external standard method. The dilutions were prepared from stock solution in the range $0.5-10 \mu \mathrm{g} / \mathrm{ml}$. The calibration curve was prepared by plotting the peak areas versus the concentrations injected. The stability of standard in solution during analysis was determined by repeated analysis of sample on the same day and also after $48 \mathrm{~h}$ of storage at laboratory conditions and in the refrigerator.

\section{Method validation:}

A stock solution of bergapten was prepared and diluted to an appropriate concentration for the generation of the calibration curve. At least five concentrations of bergapten were analyzed in triplicate. The calibration curve was analyzed using a linear regression equation and correlation coefficients.

The linearity of the method for bergapten was evaluated in between $0.5-10 \mu \mathrm{g} / \mathrm{ml}$ concentration range in triplicate where, the graph was plotted between concentration and area under the curve. Intra and inter day variations were chosen to determine the precision of the developed method. For intra-day variability test, the mixed standard solution was analyzed in triplicates within one day, while, for inter day variability analysis, the solution was examined in triplicate for three consecutive days. Variations were expressed by the relative standard deviation (RSD) for intra and inter day analysis. The deviation from the nominal concentration was defined as accuracy. The recovery test was performed by adding a known amount of standard in a measured quantity of sample in triplicate. The LOD was calculated by taking an $\mathrm{S} / \mathrm{N}$ ratio of 3 as criteria. The acceptance criteria for the LOQ were calculated by taking an $\mathrm{S} / \mathrm{N}$ ratio of 10 . Accuracy was determined by the standard addition method. The pre analyzed samples were spiked with bergapten standard of 10,20 and $30 \mu \mathrm{g} / \mathrm{ml}$ concentrations and the fortified samples were then analyzed by developed RP-HPLC method. The percent (\%) recovery of the sample and $\%$ RSD was calculated at each level. Robustness of the method was determined to evaluate the influence of small but deliberate changes in analytical conditions. The flow rate of the mobile phase was varied from 0.9 to $1.1 \mathrm{ml} / \mathrm{min}$ and composition of mobile phase was varied from 63 to $67 \%$. Environmental and chromatographic conditions were constant for the test samples and standard during HPLC analysis. The area of the peak corresponding to the $\mathrm{R}_{\mathrm{t}}$ of the standard was recorded, and content was determined using the regression equation derived from the calibration curve.

\section{RESULTS AND DISCUSSION}

To develop an efficient extraction method for bergapten from $P$. dulce various extraction methods, including HRE, SE, cold maceration, UAE and MAE were used and compared for their efficiency. For optimization of MAE, the series of preliminary experiments were performed to determine the optimum operating conditions such as extraction time, microwave power and solute-solvent ratio required for MAE.

Literature suggests that for MAE, different solvents were used to extract phytochemicals of diverse chemical nature. Transparent solvents do not absorb microwaves and hence the temperature of the solution 
remains constant. Only sample core gets heated in transparent solvents like hexane and chloroform. Polar solvents like methanol, ethanol and acetone, etc. absorb microwave and hence heating is seen in both the places i.e. solvent and plant material core ${ }^{[34]}$. Lange et al., reported closed vessel temperature in the microwave for different solvents; some of them are listed in Table $1^{[35]}$. Bergapten chemically is a coumarin (fig. 1) and have better solubility in non-polar solvents like chloroform, dichloromethane, etc. Bergapten was reported from chloroform extract of $P$. dulce bark $^{[27]}$. Therefore, chloroform was selected as the extracting solvent to optimize the parameters affecting the MAE of bergapten in $P$. dulce. The results suggested that the extraction yield of bergapten was highest $(0.004 \%$ $\mathrm{w} / \mathrm{w}$ ) at $1: 20$ sample to solvent ratio.

The microwave power controls energy supplied to the sample. It was related with the inside temperature of the microwave oven. It affects interactions and equilibrium rate and controls partition of analytes between sample and solvent. A mechanism explaining the effect of solvent-solute equilibrium and time is shown in fig. $2^{[36]}$. The quantity of analytes extracted was increased with the increasing extraction time, although degradation may occur. To optimize the extraction time, extraction was carried out at different microwave powers for different periods. Extraction was done with chloroform (40 ml) and samples were collected at intervals 2, 6, 10 min and at three different microwave powers of 190,

TABLE 1: SOLVENT BOILING POINT CLOSEDVESSEL TEMPERATURE COMPARISON

\begin{tabular}{lcc}
\hline Solvent & $\begin{array}{c}\text { Boiling } \\
\text { point }\left({ }^{\circ}\right)\end{array}$ & $\begin{array}{c}\text { Closed-vessel temperature } \\
\left({ }^{\circ}\right) \text { at } 175 \text { psig }\end{array}$ \\
\hline Cyclohexane & 80.7 & - \\
Petroleum ether & $35-52$ & - \\
Dichloromethane & 39.8 & 140 \\
Acetone & 56.2 & 164 \\
Methanol & 64.7 & 151 \\
\hline
\end{tabular}

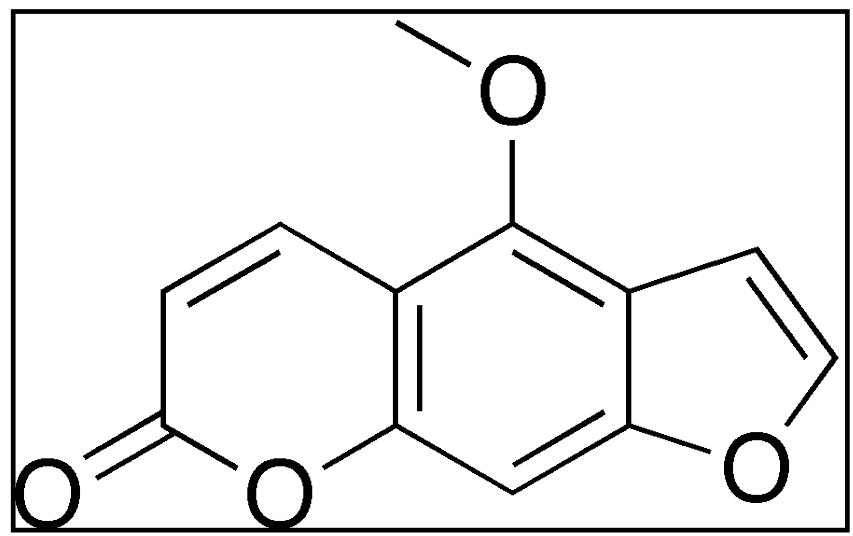

Fig. 1: Chemical structure of bergapten.

September-October 2016

Indian Journal of Pharmaceutical Sciences 
quantification of bergapten by testing combination of many solvents. The chromatogram (fig. 3) obtained with acetonitrile-water $(65: 35 \%)$ was found to have good symmetry with lowest $\mathrm{R}_{\mathrm{t}}(5.33 \mathrm{~min})$ and sharp, well-defined peak. The standard was stable for $48 \mathrm{~h}$ storage at laboratory temperature and under refrigerator temperature in acetonitrile:water $(65: 35 \%)$ mixture.
The accuracy of the procedure determined by recovery analysis, afforded recovery of 100.82-102.50\% after spiking the additional standard solution to the previously analyzed test solution. The RSD values were in the range of 0.95-1.01 (Table 3) indicating, the proposed method has good accuracy. The precision of the method was evaluated by repeated injections of

TABLE 2: DETERMINATION OF EXTRACTION EFFICIENCY BY DIFFERENT EXTRACTION TECHNIQUES

\begin{tabular}{|c|c|c|c|}
\hline \multicolumn{2}{|c|}{ Extraction technique } & Time (min) & Bergapten $(\%, \mathrm{mg} / \mathrm{g})$ \\
\hline \multirow[t]{9}{*}{ MAE } & $190 \mathrm{~W}$ & 2 & 0.0018 \\
\hline & & 6 & 0.0029 \\
\hline & & 10 & 0.0024 \\
\hline & $350 \mathrm{~W}$ & 2 & 0.0023 \\
\hline & & 6 & 0.0028 \\
\hline & & 10 & 0.0027 \\
\hline & $700 \mathrm{~W}$ & 2 & 0.0010 \\
\hline & & 6 & 0.0026 \\
\hline & & 10 & 0.0040 \\
\hline \multirow{3}{*}{\multicolumn{2}{|c|}{ UAE }} & 20 & 0.0013 \\
\hline & & 40 & 0.0031 \\
\hline & & 60 & 0.0040 \\
\hline \multirow{3}{*}{\multicolumn{2}{|c|}{ Maceration }} & 360 & 0.0018 \\
\hline & & 720 & 0.0028 \\
\hline & & 1440 & 0.0039 \\
\hline \multirow{4}{*}{\multicolumn{2}{|c|}{ HRE }} & 120 & 0.0015 \\
\hline & & 240 & 0.0027 \\
\hline & & 360 & 0.0042 \\
\hline & & 180 & 0.0017 \\
\hline \multirow{4}{*}{ SE } & & 360 & 0.0027 \\
\hline & & 540 & 0.0038 \\
\hline & & 720 & 0.0040 \\
\hline & & 1440 & 0.0040 \\
\hline
\end{tabular}

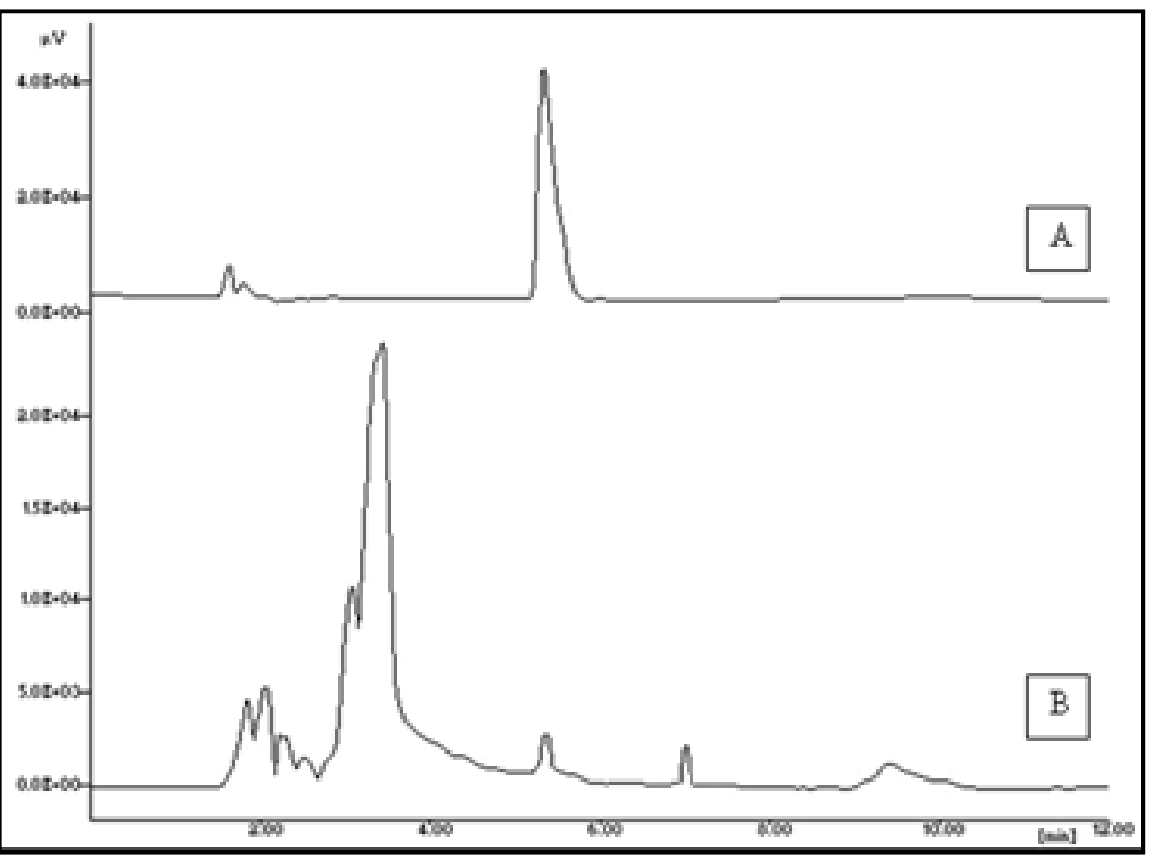

Fig. 3: RP-HPLC chromatogram.

A: chromatogram of bergapten; B: chromatogram of $P$. dulce barks extract. 
TABLE 3: RECOVERY (ACCURACYISTANDARD ADDITION) OF BERGAPTEN

\begin{tabular}{ccccccc}
\hline Analyte & Amt contained $(\mu \mathrm{g})$ & Amt added $(\boldsymbol{\mu g})$ & Found $(\boldsymbol{\mu g})$ & Recovery $(\%)$ & Average recovery & RSD $(\%)$ \\
\hline Bergapten & 0.84 & 10 & 5.28 & 102.96 & 102.50 & 1.09 \\
& 0.84 & 10 & 5.39 & 102.0 & & \\
& 0.84 & 10 & 5.3 & 102.56 & & 1.01 \\
& 0.84 & 20 & 10.14 & 100.0 & 100.24 & \\
& 0.84 & 20 & 10.33 & 100.12 & & 0.95 \\
& 0.84 & 20 & 10.15 & 100.6 & & 101.05 \\
& 0.84 & 30 & 15.29 & 101.01 & & \\
\hline
\end{tabular}

TABLE 4: PRECISION (INTERDAY, INTRADAY), LOD AND LOQ OF BERGAPTEN

\begin{tabular}{ccccccc}
\hline \multirow{2}{*}{ Analyte } & \multicolumn{4}{c}{ Precision (RSD, \%) } & \multirow{2}{*}{ LOD $(\mu \mathrm{g} / \mathrm{ml})$} & \multirow{2}{*}{ LOQ $(\mu \mathrm{g} / \mathrm{ml})$} \\
\cline { 2 - 5 } & \multicolumn{2}{c}{ Intraday $(\mathrm{n}=3)$} & & & \\
\cline { 2 - 5 } & $\mathrm{Rt}$ & $\mathrm{Pa}$ & $\mathrm{Rt}$ & $\mathrm{Pa}$ & & \\
\hline Bergapten $(10 \mu \mathrm{g} / \mathrm{ml})$ & 0.12 & 1.35 & 0.13 & 1.15 & 1.0 & 3.77 \\
\hline
\end{tabular}

the sample solution for three times. The RSD values of peak area were $<1.5 \%$. The small value of $\%$ RSD indicates that the validated method has good precision. LOD and LOQ of bergapten for the developed method were found to be 1.0 and $3.77 \mu \mathrm{g} / \mathrm{ml}$, respectively. It is suggested that the method can be effectively used in a wide concentration range of bergapten for its detection and quantification. The results for precision, LOD and LOQ are summarized in Table 4. The developed method was robust with no significant change in the retention time of bergapten and the profile of the extract was observed by changing the mobile phase and flow rate. The developed method has not only showed high recovery and accuracy but also found to be suitable for reliable analysis of bergapten in $P$. dulce samples.

The developed MAE method found to be efficient for the extraction of bergapten. Bergapten was quantified using newly developed RP-HPLC method. The optimum MAE conditions were found to be a microwave power of $700 \mathrm{~W}$, extraction time of $10 \mathrm{~min}$ and the solid-liquid ratio of $1: 20(\mathrm{~g} / \mathrm{ml})$. Benefits of MAE technique for sample preparation in comparison to the conventional extraction method were reduced extraction time, high extraction efficiency, reduced solvent consumption, efficient sample preparation and large-scale industrial applicability. The developed and validated RP-HPLC method was found to be accurate, sensitive, selective and precise for the quantification of bergapten in $P$. dulce. The analytical method can be a tool for fast and precise method of quality control for commercialized $P$. dulce samples.

\section{Acknowledgements:}

Authors thank Prof. Dr. G. Iyer, Mumbai for plant authentication.

\section{Financial support and sponsorship:}

Nil.

\section{Conflicts of interest:}

The author declares no competing interests.

\section{REFERENCES}

1. Shehadeh MB, Afifi FU, Abu Hamdah SM. Platelet aggregation inhibitors from aerial parts of Ruta chalapensis grown in Jordan. Integrat Med Insight 2007;2:35-9.

2. Joh EH, Gu W, Kim DH. Echinocystic acid ameliorates lung inflammation in mice and alveolar macrophages by inhibiting the binding of LPS to TLR4 in NF- $\kappa \mathrm{B}$ and MAPK pathways. Biochem Pharmacol 2012;84:331-40.

3. Nascu BRD, Cobzac SC, Baciu S. Optimum ultrasoundassisted extraction conditions of some flavonoids from green tea leaves. Control quality of green tea product by TLC fingerprinting. Ana Let 2011;44:2865-75.

4. Santaladchaiyakit Y, Srijarana S. A simplified ultrasoundassisted cloud point extraction method coupled with highperformance liquid chromatography for residue analysis of benzimidazole anthelmintics in water and milk samples. Anal Method 2012;4:3864-73.

5. Wu R, Zhang ZQ. Microwave-assisted extraction and highperformance liquid chromatography for simultaneous determination of osthole and isoimperatorin in Libanotis buethorimensis. Anal Let 2010;43:34-44.

6. Eskilsson CS, Bjorklund E. Analytical-scale microwaveassisted extraction. J Chromatograph A 2000;902:227.

7. Ganzler K, Szinai I, Salgo A. Effective sample preparation method for extraction biologically active compounds from different matrixes by a microwave technique. J Chromatograph A 1990;520:257-62.

8. Pan X, Liu H, Jia G, Shu YY. Microwave-assisted extraction of glycyrrhizic acid from licorice root. Biochem Eng J 2000;5:173-7.

9. Song JZ, Mo SF, Yip YK, Qiao CF, Han QB, Xu HX. Development of microwave assisted extraction for the 
simultaneous determination of isoflavonoids and saponins in Radix astragali by high-performance liquid chromatography. J Sep Sci 2007;30:819-24.

10. Talebi M, Ghassempour A, Talebpour Z, Dolatyari AL. Optimization of the extraction of paclitaxel from Taxus baccata Linn. by the use of microwave energy. J Sep Sci 2004;27:1130-6.

11. Liao CD, Lin HY, Chiueh LC, Shih DC. Simultaneous quantification of aflatoxins, ochratoxin $\mathrm{A}$ and zearalenone in cereals by LC-MS/MS. J Food Drug Ana 2011;19:259-68.

12. Pan Y, Zhang J, Shen T, Zuo ZT, Jin H, Wang YZ, et al. Optimization of Ultrasonic extraction by response surface methodology combined with ultra-fast liquid chromatographyultraviolet method for determination of four iridoids in Gentiana rigescens. J Food Drug Anal 2015;23:529-37.

13. Barroso MF, Sales MGF, Almeida SAA, Vaz MCVF, Delerue MC. Maltol determination in food by microwave assisted extraction and electrochemical detection. J Food Drug Anal 2008;16:30-6.

14. Misra GI, Nigam SK. Pithecolobium dulce a tree of commercial importance. Quart J Crude Drug Res 1978;16:158-62.

15. Nadkarni KM. Indian Materia Medica. 3rd ed. Bombay: Popular Prakashan Pvt Ltd; 1982. p. 978.

16. Goyal P, Kachhwaha S, Kothari SL. Micro-propagation of Pithecellobium dulce (Roxb.) Benth a multipurpose leguminous tree and assessment of genetic fidelity of micro propagated plants using molecular markers. Physiol Mol Bio Plants 2012;18:169-76.

17. Nigam SK, Gupta RK, Mitra CR. Pithecellobium dulceIsolation and characterization of the constituents of the legume. J Pharm Sci 1962;52:459.

18. Brewbaker JL. Nitrogen-fixing Tree Improvement and Culture in Tree Breeding Practices. Hawaii: Elsevier; 2004. p. 1490-501.

19. Banarjee A. Studies on alkylated resin from Pithecellobium dulce. J Indian Chem Soc 2005;82:186-7.

20. Barrera NLL, Bautista BS, Jimenez EM, Rayes CR. Influence of leaf, fruit and seed powders and extracts of Pithecellobium dulce (Roxb.) Benth. (Fabaceae) on the in vitro vegetative growth of seven postharvest fungi. Revista Mexicana de Fitopatologia 2002;20:66-71.

21. Pithayanukul P, Ruenraroengsak P, Bavovada R, Pakmanee N, Suttisri R, Saenoon S. Inhibition of Naja kaouthia venom activities by plant polyphenols. J Ethnopharmacol 2005;97:527-33.

22. Govindarajan M, Sivakumar R, Rajeswary M, Yogalakshmi
K. Adulticidal activity of Pithecellobium dulce (Roxb.) Benth. against Culex quinquefasciatus (Say). Asian Pacific J Trop Dis 2012;1:124-8.

23. Manna P, Bhattacharyya S, Das J, Ghosh J, Sil PC. The phytomedicinal role of Pithecellobium dulce against $\mathrm{CCl}_{4}$ mediated hepatic oxidative impairments and necrotic cell death. Evid Based Comple Alter Med 2011;2011:1-17.

24. Sugumaran M, Vetrichelvan T, Quine SD. Free radical scavenging activity of folklore: Pithecellobium dulce Benth. Leaves. Ethnobot Leaflet 2008;12:446-51.

25. Katekhaye SD, Nagmoti DM. $\alpha$-Glucosidase and $\alpha$-amylase inhibition activities of Pithecellobium dulce bark and leaves. Phytopharmacol 2013;4:123-30.

26. Katekhaye S, Kale M. Antioxidant activity, free radical scavenging potential, total phenolic, and flavonoid content of Pithecellobium dulce (Roxb.) Benth. Free Rad Antioxi 2012;2:1-11.

27. Katekhaye S, Laddha K. Coumarins and a triterpenoid from Pithecellobium dulce. Chem Nat Comp 2015;51:956-8.

28. Nigam SK, Misra G, Uddin R, Yoshikawa K, Kawamoto M, Arihara S. Pithedulosides A-G, Oleanane glycosides from Pithecellobium dulce. Phytochem 1997;44:1329-34.

29. Niranjan PS, Kazuo K, Zhonghua J, Sukdeb B, Basudeb A, Tamotsu N. A minor acylated triterpenoid saponin from the seeds of Pithecellobium dulce. J Chem Res 1999;32:558-9.

30. Katekhaye S, Laddha K. Prenylated flavonoids from bark of Pithecellobium dulce. Nat Prod J 2014;4:43-6.

31. Steynberg PJ, Steynberg JP, Brandt EV, Ferreira D, Hemingway RW. Oligomeric flavanoids. Part 26. Structure and synthesis of the first profisetinidins with epifisetinidol constituents units. J Chem Soc 1997;1:1943-50.

32. Katekhaye SD, Paul AT, Laddha KS. Lupane analogue from bark of Pithecellobium dulce and in vitro $\alpha$-glucosidase and $\alpha$-amylase enzyme inhibition assay of extract for potential antidiabetic activity. Chem Nat Comp 2016;52:205-7.

33. Nigam SK, Mitra CR. Pithecellobium dulce. IV. Constituents of flowers, heartwood and root bark. Planta Med 1968;16:335-7.

34. Mandal V, Mohan Y, Hemalatha S. Microwave assisted extraction - An innovative and promising extraction tool for medicinal plant research. Pharmacog Rev 2007;1:7-18.

35. Dean JA. Lange's Handbook of Chemistry. 15th ed. New York: McGraw Hill; 1992.

36. Wilson ID. Encyclopedia of Separation Science. San Diego: Academic Press; 2000. 